\title{
Matching theory: kidney allocation
}

\author{
Kyle Luong (Meds 2016) \\ Faculty Reviewer: Dr. Gregory Pavlov, PhD (Department of Economics)
}

\begin{abstract}
Lloyd Shapley and Alvin E. Roth have recently been awarded the Nobel Prize in Economics for their work in matching theory. Although branching from the field of economics, matching theory has had many implications in the world of medicine. For example, the National Residency Matching Program in the United States is an application of matching theory. The focus of this article is the application of matching theory to kidney transplant allocation. Kidney transplantation is the best treatment for end stage renal failure. Unfortunately, the demand for kidneys exceeds supply. Kidney paired exchange programs, which have begun to garner great success in increasing the number of kidney transplants worldwide, base their foundations on matching theory. Overviewed in this paper will be how these programs were created and work, their successes, and some of the unique challenges and logistical obstacles they face.
\end{abstract}

\section{INTRODUCTION}

Traditionally, markets function with monetary exchange facilitating the movement of goods to buyers from sellers. However in some instances monetary exchange is unfeasible due to the nature of the market and as a result, prototypical market structure is inapplicable. Matching theory is a branch of game theory that deals with this non-price allocation. Pioneered by Lloyd Shapley in the 1950s and 1960s, it has been applied to real markets with great success. Two medical markets where matching theory has garnered this success are residency matching and kidney transplant allocation whose designs owe greatly to Alvin E. Roth, an American economist who made great forays into the application of Shapley's theories and their further development. Recently, both men were awarded the Nobel Prize in Economics for their work. In light of its contemporary step back into the public eye, this article will briefly outline matching theory with some examples from real markets. Finally, the application of matching theory to kidney transplant allocation will be explored, with a discussion of its success and future directions.

\section{MATCHING THEORY: BASICS}

Shapley's theory is based on stable matching. In their 1962 paper, Gale and Shapley demonstrated this idea with the stable marriage problem. ${ }^{1}$ The stable marriage problem asked how a number of women could be matched to a number of men, considering their respective preferences for each member of the opposite sex. They showed that no matter the preferences, there would always exist a stable allocation. A stable allocation is one whereby no parties can be better off by further exchange. Stability is desirable in this example and its real world extrapolations as stability is seen as an indication of efficiency because further improvement of happiness from exchange is impossible. Additionally, stability imparts robustness to allocation systems since it eliminates incentives for parties to disobey or manipulate the rules of the system. In the stable marriage problem, the solution was the Gale-Shapley "deferred acceptance" algorithm. Suppose the men are allowed to propose to the women. Each man would propose to his favourite woman. A woman with more than one proposal would keep her favourite proposal 'on hold' without accepting, and rejecting all others. (Women with only one proposal would keep that proposal on hold as well.) With the second round of proposals, men who were rejected in the preceding round would propose to their second ranked woman. The women behave similarly as before, keeping their best proposal on hold and rejecting the rest, including any proposals from previous rounds. Eventually, all women will have been proposed to at which point they are all required to accept their on hold proposals. It was shown that all matches made in this manner were stable. An implication of the Gale-Shapley algorithm was that the proposing party would secure more favourable matches.

\section{MATCHING THEORY: APPLICATION}

At the crux of this deferred acceptance algorithm is free trading. In the stable marriage problem, the women were able to trade tentative proposals for anything better that came along. Although the marriage problem may seem contrived, it indeed has real world counterparts. One such market is residency matching in the US. Roth demonstrated that the matching algorithm used by the National Resident Matching Program (NRMP) was able to make stable matches because it was essentially an adaptation of the Gale-Shapley algorithm. ${ }^{2}$ The allocation of residency positions was another stable marriage problem, with the hospitals proposing to the applicants. Harkening back to the stable marriage problem, Roth noted that the algorithm produced outcomes favouring hospitals. Moreover, with more physician couples wishing to match to the same areas, the algorithm was proving insufficient in meeting these new needs. In 1995, Roth and Elliot Peranson were enlisted to redesign the NRMP to accommodate couple matching. Their algorithm was adopted in 1997 and used ever since. ${ }^{3}$

\section{KIDNEY TRANSPLANT}

The best treatment for end stage renal failure is kidney transplant. $\mathrm{Pa}$ tients receiving transplants live 10 years longer than those on dialysis. ${ }^{4}$ Unfortunately, the demand for kidneys outpaces the supply of deceased donors with over $70 \%$ of Canadians who are on organ waiting lists, needing a kidney. ${ }^{5}$ Living donors are another resource, providing $>16$ years of dialysis-free survival compared to the 8.6 years from a deceased donor. ${ }^{6}$ Unfortunately, the challenge with utilizing this pool of living donors was that many pairs of willing donors and recipients were deemed incompatible after screening. Information from these donors was usually not recorded for follow up and the pair would be sent home. ${ }^{7}$ With such congestion on the deceased donor waiting list, there was an urgent need to better utilize living donors.

A solution to the problem would be another application of Gale 


\section{HEALTH POLICY AND ECONOMICS}

and Shapley's matching theory. Whereas the marriage problem and the NRMP represented a two-sided market (two parties matching with one another), the kidney exchange problem is one-sided as every individual and their initial donor candidate is regarded as a single item. Gale's toptrading cycle algorithm, which also produces stable matches, was the answer to this modified allocation problem. Objects are initially distributed to each entity and like the deferred acceptance algorithm, subsequent trading occurs. ${ }^{8}$ In kidney transplantation, the initial allocation of objects is analogous to the pairs of incompatible donors and their intended recipients. Now, imagine two incompatible pairs of a donor and recipient. If each donor happened to be a match for the recipient in the other pair, a mutually beneficial exchange would be possible whereby both patients receive a compatible donor. This system of exchanges has been dubbed Kidney Paired Exchange (KPE). Exchanges could and have become more complicated, with further pairs participating in a daisy chain of trades. KPE has also been adapted to make use of the growing number of altruistic or non-directed donors. ${ }^{9}$ In domino-paired donation, the altruistic donor donates the kidney to a recipient of an incompatible pair. The donor of said pair would then donate their kidney to a compatible recipient on the waitlist. Longer domino chains have been accomplished, with the longest to date spanning 30 kidneys and 60 individuals. ${ }^{10}$

\section{SUCCESS}

Since it was first suggested by Rapaport in $1986,{ }^{11}$ several informal exchanges have been reported. ${ }^{12}$ Not until 2005 was the first national KPE program established in the Netherlands. ${ }^{13}$ In the US, Roth helped design the New England Program for Kidney Exchange, ${ }^{14}$ and along with the Ohio program was one of the early preludes to the national program proposed by UNOS in 2010. In Canada, a three province pilot program initiated in 2009 and has become nationwide as of October $2010 .{ }^{15}$ The American programs have seen increased numbers of kidney exchanges in each subsequent year with $>1000$ cumulative transplants since 1998 .

${ }^{12}$ Researchers suggest that optimal utilization of the program could see as many as 1000-2000 additional transplants per year in the US; ${ }^{16}$ saving the country $\$ 750$ million USD in dialysis costs annually. ${ }^{17}$ With the Canadian program still in its infancy, there is insufficient data to evaluate its success. To date, the Canadian Living Paired Donor Exchange Registry has facilitated 144 transplants with 14 more scheduled before the end of the year. Increased transplants mean more patients are experiencing a lessened burden of dialysis, better mortality, and a higher quality of life. ${ }^{18}$

\section{CHALLENGES AND FUTURE DIRECTIONS}

KPE program implementation elicits various challenges. One implication that arose was that all transplants would have to be done simultaneously to prevent donor reneging. Only recently have non-simultaneous donations been performed with altruistic donors being incorporated into non-simultaneous extended altruistic donor (NEAD) chains. NEAD resembles domino-paired exchange except the last donor in the chain does not donate to a waiting list recipient, but rather becomes a bridge donor, awaiting more pairs. Optimistically, the potential for extending the wave of exchanges outweighs the risk of donor reneging. Some argue however, to not be overconfident because of the honeymoon phase where a single donor is able to initiate a large chain of donations. Many chains will not propagate indefinitely and bridge donors accumulate as matches become rarer. Many drop out after some period of time. ${ }^{19} \mathrm{~A}$ national KPE exchange also presents the need for co-ordination between the various transplant centers and a centralized registry. It is no surprise that additional viable exchanges are easier to find with a larger pool of pairs. However, there needs to be incentives for hospitals to enroll donor-recipient pairs instead of performing short chain exchanges internally. As well, the transport of donors across the country presents an- other challenge both logistically and financially. These are all issues that need to be addressed if KPE is to be used to its full potential.

\section{CONCLUSION}

This article has provided an introduction to matching theory and the ways it has been applied in real markets, with special regard to kidney transplant allocation. The discussion of KPE's permutations, successes and shortcomings here are definitely not exhaustive. For instance, the ethical issues associated with KPE have not been addressed here. Further reading is encouraged for those interested. Ultimately, matching theory proves to be applicable in many contexts, and has especially found some utility in the field of kidney transplantation.

\section{REFERENCES}

1. Gale D, Shapley LS. College admissions and the stability of marriage. Am Math Mon. 1962 Jan;69(1):9-15.

2. Roth AE. The Evolution of the Labor Market for Medical Interns and Residents: A Case Study in Game Theory. JPE. 1984;92(6):991-1016.

3. Roth AE, Peranson E. The Redesign of the Matching Market for American Physicians: Some Engineering Aspects of Economic Design. Am Econ Rev. 1999 Sep;89(4):748-780.

4. Wolfe RA, Ashby VB, Milford EL et al. Comparison of mortality in all patients on dialysis, patients on dialysis awaiting transplantation, and recipients of a first cadaveric transplant. N Engl J Med. Dec 1999;341(23):1725-1730.

5. CIHI.ca [Internet]. Canadian Institute for Health Information. c1996-2013 [cited 2012 Dec 16]. Available from: www.cihi.ca.

6. SRTR. 2008 Annual Report of the U.S. Organ Procurement and Transplantation Network and the Scientific Registry of Transplant Recipients: Transplant Data 1998-2007. Rockville, MD: Health Resources and Services Administration, Healthcare Systems Bureau, Division of Transplantation.

7. Roth AE. What have we learned from market design? Economic Journal (Royal Economic Society). 2008 Mar;118(527):285-310.

8. The Prize in Economic Sciences 2012 - Popular Information [Internet]. The Royal Swedish Academy of Sciences; 2012 [cited 2012 Dec 16]. Available from: http://www.nobelprize.org/nobel_prizes/economics/laureates/2012/ popular.html.

9. Matas AJ, Garvey CA, Jacobs CL, Kahn JP. Nondirected donation of kidneys from living donors. N Engl J Med. 2000 Aug;343(6):433-36.

10. Sack K. 60 Lives, 30 Kidneys, All Linked. NYT. 2012 Feb 19;Sect. A:1.

11. Rapaport FT. The case for a living emotionally related international kidney donor exchange registry. Transplant Proc. 1986 Jun;18(3 Supp 2):5-9.

12. Wallis CB, Samy KP, Roth AE, Rees MA. Kidney paired donation. Nephrol Dial Transplant. 2011 Jul;26(7):2091-2099.

13. de Klerk M, Keizer KM, Claas FH, et al. The Dutch national living donor kidney exchange program. Am J Transplant. 2005 Sep;5(9):2302-2305.

14. Roth AE, Sonmez T, Unver MU. Kidney Exchange. Q J Econ 2004;119(2):457-488.

15. Fortin MC, Williams-Jones B. Who should travel in kidney exchange programs: the donor, or the organ? Open Med. 2011;5(1):e23-e25.

16. Segev DL, Kucirka LM, Gentry SE, Montgomery RA. Utilization and outcomes of kidney paired donation in the United States. Transplantation. 2008 Aug;86(4):502-510.

17. Goldfarb DA. Kidney paired donation and optimizing the use of live donor organs. J Urol. 2005 Nov;174(5):1911-1912.

18. Tonelli M, Wiebe N, Knoll G, Bello A, Browne S, Jadhav D, et al. Systematic Review: Kidney Transplantation Compared With Dialysis in Clinically Relevant Outcomes. Am J Transplant. 2011 Jun;11:2093-2109.

19. Gentry SE, Segev DL. The Honeymoon Phase and Studies of Nonsimultaneous Chains in Kidney-Paired Donation. Am J Transplant. 2011 


\section{Bluewater Health Sarnia \& Petrolia, Ontario}

Bluewater Health is recruiting for the following positions to provide services to the residents of Sarnia-Lambton both in the community and at the hospital.

- Dermatologist

- Paediatrician

- Rheumatologist

- Hospitalists
- Neurologist

- Psychiatrist

- Emergency Physicians

- Family Physicians (Petrolia) - including low acuity Emergency

Bluewater Health is a 320 bed hospital operating on 2 sites which includes a recently completed $\$ 319$ million redevelopment. The hospital offers excellent medical and diagnostic supports:

- A broad range of diagnostic services, including CT and MRI.

- Full spectrum of specialists available 24/7 (neurosurgery not available)

Sarnia was rated the Most Livable City in Ontario by the Pembina Institute (August 2007). Situated on the shores of Lake Huron at the border to Michigan, Sarnia offers excellent quality of life, sports, arts and culture, education, state of the art health care,

and beautiful natural environment

To inquire about these positions, please contact:

Dr. Mark Taylor, Chief of Professional Staff

Bluewater Health

Medical_affairs@bluewaterhealth.ca

519-464-4400 ext 4534.

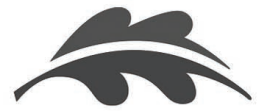

B LUEWATER

H E A L T H

Life, health and renewal. 